\title{
Validation of a semi-quantitative food-frequency questionnaire for use among adults in Guatemala
}

\author{
Monica M Rodríguez ${ }^{1}$, Humberto Méndez ${ }^{1}$, Benjamín Torún ${ }^{1}$, Dirk Schroeder ${ }^{2}$ and \\ Aryeh D Stein ${ }^{2, *}$ \\ ${ }^{1}$ Institute of Nutrition of Central America and Panama (INCAP), Guatemala City, Guatemala: ${ }^{2}$ Department of \\ International Health, Rollins School of Public Health, Emory University, 1518 Clifton Road NE, Atlanta, GA 30322, \\ USA
}

Submitted 2 May 2001: Accepted 29 January 2002

\begin{abstract}
Objective: The purpose of the study was to assess the validity of a 52-item semiquantitative food-frequency questionnaire (FFQ) by comparing it with multiple 24hour dietary recalls.

Design: Three non-consecutive 24-hour dietary recalls and one FFQ were administered over a one-month period.

Setting: Four communities of El Progreso, Guatemala.

Subjects: Seventy-three individuals aged $22-55$ years.

Results: Intakes of energy and other nutrients as measured by the FFQ were higher than intakes measured by 24-hour recalls. Energy was overestimated by $361 \mathrm{kcal}$, and nutrient overestimates were particularly great for vitamin $\mathrm{C}$ and iron. Pearson correlation coefficients for crude energy and nutrients intakes ranged from 0.64 for energy to 0.12 for vitamin C. Exact agreement for both methods (measured by the concordance correlation coefficient) ranged from 0.59 (fat) to 0.06 (vitamin C). Pearson correlation coefficients for energy-adjusted nutrients ranged from 0.59 (carbohydrates) to 0.11 (thiamin). Pearson correlation coefficients for the proportion of total energy derived from specific foods ranged from 0.59 (tortillas) to 0.01 (sugared beverages). Cross-classification of quartiles of crude nutrient intakes for both methods indicated that $<11 \%$ were grossly misclassified; after adjusting for energy intake, $<13 \%$ were grossly misclassified.

Conclusions: This FFQ provides good measures of energy and macronutrient intakes and a reasonably reliable measure of micronutrient intake, indicating its suitability for comparing exposures within a study population in reference to heath-related endpoints. Our results highlight the need to adapt any FFQ to specific cultural needs - in this case, the Guatemalan 'core foods' (tortilla, bread and beans), for which interindividual variability in intake is high.
\end{abstract}

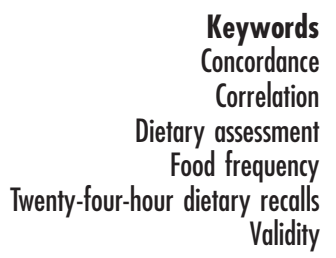

Food-frequency questionnaires (FFQs) have become popular for the assessment of usual dietary intakes. The theory underlying their use relates to their use of a longer reference period than is typically used in dietary recall or diet record approaches, obviating the need for multiple days of data collection. Since an FFQ ascertains dietary habits over a longer reference period, this instrument is commonly used for epidemiological studies of the relation between habitual diet and disease. A 24-hour recall estimates more accurately the intake of individuals over a short period of time, but more days of data collection are needed to estimate habitual intakes due to the variability within a person ${ }^{1}$. Many studies have compared food and nutrient intake estimates derived from FFQs with those derived from measures usually considered more accurate, namely multiple 24-hour dietary recalls or records. In
North America, Europe, Asia and Mexico, FFQs have been shown to provide good measures of energy and macronutrient intakes and a reasonable measure of micronutrient intake $\mathrm{e}^{2-13}$.

Most FFQs were developed and have been validated for use in industrialised countries. It has been argued that FFQs may need to be developed and validated specifically for each region, in order to be culturally sensitive and to correspond to the prevailing food culture ${ }^{14,15}$. Issues such as increased seasonality of food supply and limited variability of the diet from day to day might alter the utility of FFQ approaches. We were unable to identify any publications relating to validation of an FFQ for use in Central America, and only one for a Latin American country $^{2,16}$. We therefore conducted a validation of a semiquantitative FFQ designed for use in our ongoing studies 
of the usual food intake of populations in the eastern area of Guatemala.

\section{Methods}

\section{Development of the FFQ}

The time frame considered was the three months prior to the interview. A 52-item food list was developed from the list of foods contributing more than $1 \%$ of energy intake for men and women studied in previous (unpublished) investigations in this region. The Guatemalan diet is characterised by a major reliance on several 'core foods', namely maize, wheat products, beans and sugar. At a national level, these four groups provide $74 \%$ of the daily energy intake of the population ${ }^{17}$. In rural areas, maize alone provides $45 \%$ of the total energy intake, while in the urban areas it provides $24 \%$ of energy intake. Interindividual variability in the consumption of these core foods, rather than variation in the type of foods consumed, thus plays a large role in determining inter-individual variation in nutrient intakes. To capture this high interindividual variation, both individual portion size (relative to a standard serving) and total portions eaten were ascertained. A standard portion size was presented to the respondent, who was asked how many times that portion size was eaten at each occasion. For example, respondents were asked 'How many tortillas do you eat at a meal?' The standard portion size for each food was that most commonly reported in 24-hour recalls obtained in previous studies in these communities, in which quantitative estimates of food portions were calculated using measuring devices. Respondents were asked to report their consumption as 'never or rarely consumed' or in the units of their choice, as occasions per month, week or day, rather than being restricted to specific frequency ranges. Summary questions and questions for checking the consistency of answers were asked during the interview using the FFQ, but these were not used in the computation of nutrient intakes.

Respondents in regions subject to marked seasonal variability may be less able to integrate consumption over 12 months than are respondents in settings with less variability. The question of seasonable variability is addressed in our study by using a time reference of three months, rather than the one year that is common in developed countries. Consequently, the list of foods provided to them needs to reflect current availability, or be provided by the respondents themselves in an open format. We adopted the latter approach. Individuals were asked to report which vegetables and fruits they ate during the reference period, rather than respond to a fixed list as is often used in Western studies, and then were asked to report frequency of consumption and portion sizes of these vegetables and fruits in an open-ended format. Other items presented on the FFQ were presented in a close-ended format, although the FFQ concluded with an open-ended section where other foods not common in this area might be added. Questionnaires with openended portion sizes have performed better than questionnaires with fixed portion sizes in Hispanic populations in the USA ${ }^{18}$.

\section{4-hour recalls}

The methodology for 24-hour recalls developed at the Institute of Nutrition of Central America and Panama (INCAP) for family consumption studies and for individual intake was used in this study ${ }^{19}$. In this method, interviewers ascertain food that was prepared in the house the previous day, from the time the first person in the household ate something until night, and then the intake for the individual of interest is derived as a proportion of the whole preparation. Additional questions concerning consumption of packaged foods and foods prepared outside the house are also incorporated.

Three non-consecutive 24-hour recalls were collected within one month to reduce intra-individual day-to-day variation in the reference measure ${ }^{1,4}$. The decision to collect reference data over one month, rather than the same three-month period ascertained by the FFQ, was based on logistical considerations, especially availability of staff. The 24-hour recalls were collected to represent both weekend and weekday intakes. Interviews were conducted by interviewers trained to solicit detailed information about preparation practices and prevalent regional or ethnic foods. The first 24-hour recalls were unannounced, but subsequent visits were scheduled. The FFQ was interviewer-administered after the third 24-hour recall had been completed.

The interviewers were supervised by a nutritionist to check interview quality and the forms were checked before data entry.

\section{Study population}

One hundred individuals (50 men and 50 women) were selected from a volunteer group from the resident population of four communities of El Progreso district, Guatemala. These communities have participated in several INCAP-sponsored studies over the past 35 years. Addresses were identified from a recent census in each village. To be eligible for this study, individuals had to be couples (man and woman) sharing the same household and be between 20 and 55 years old. After excluding individuals who were ill (by self-report) on the day of the interview or who could not provide complete dietary information from the previous 24 hours, 85 individuals provided data for the FFQ and at least two days of 24-hour recalls. Once nutrient estimates were derived, we further excluded men who reported more than $4000 \mathrm{kcal}$ and women who reported more than $3500 \mathrm{kcal}$ in both methods, resulting in usable data from 73 individuals for analysis. Their ages ranged from 22 to 55 (mean $32 \pm 7$ ) years; $41 \%$ were male and $59 \%$ were female. 


\section{Statistical methods}

The Food Composition Table for the Central American area $^{20}$ was used to derive nutrient and energy estimates from the dietary data. The same database was used for both instruments. Descriptive statistics were computed. Group mean intakes of energy and nutrients estimated by 24-hour recall were compared with those obtained from the semi-quantitative FFQ using the paired-sample $t$-test. These analyses were also repeated after adjustment of nutrient intakes for total energy intake using the residuals method $^{1}$.

We computed the Pearson correlation coefficient for both the unadjusted and the energy-adjusted nutrient estimates across both methods, and corrected these estimates for residual measurement error in the 24-hour recalls using the approach described by Willett ${ }^{1}$. To improve normality, the distributions of carbohydrates, calcium, thiamin and vitamins $\mathrm{C}$ and $\mathrm{A}$ were logtransformed before analysis; intakes of other nutrients analysed were reasonably normally distributed. The concordance correlation coefficient, which provides a simultaneous assessment of both bias and precision ${ }^{21}$, was calculated to estimate the degree of exact agreement between estimates derived from the FFQ and the dietary recalls. The concordance coefficient is a quantitative measure of departure from the $45^{\circ}$ line passing through the origin. As such, it weights observations by both their value and their deviance from the predicted value. The concordance coefficient reduces to a weighted kappa statistic when the variables being compared are ordinal rather than continuous. We generated Bland-Altman plots $^{22}$ to visually assess whether mean values were predictive of intra-individual differences in intake.

We categorised the distributions of nutrient intakes into quartiles, and compared the degree of exact agreement across quartiles. In such analyses, the exact agreement expected due to chance (i.e. the number of individuals who fall on the main diagonal of a 4 by 4 cross-tabulation) is 25\%. SAS 8.0 and SPSS 10.0 for Windows were used for statistical analysis.

\section{Results}

Mean energy and nutrient intakes, as measured with at least two non-consecutive 24-hour recalls and the FFQ, are presented in Table 1. Of the 73 subjects, 62 (85\%) completed three 24-hour recalls and 11 (15\%) completed two 24-hour recalls.

For each nutrient examined, estimated energy and nutrient intakes derived from the FFQ were higher than estimates derived from 24-hour recalls. Energy was overestimated by $361 \mathrm{kcal}(1.51 \mathrm{MJ})$, and nutrient overestimates were particularly great for vitamin $\mathrm{C}$ and iron. Bland-Altman plots confirmed the relative overestimation of FFQ across the range of intakes.

Table 2 presents the results of correlations between crude nutrient intakes obtained from the FFQ and the 24hour recalls. The Pearson correlation coefficients for energy and crude nutrient intakes range from 0.64 for energy to 0.12 for vitamin C. Correlations above 0.50 were found for energy, protein, fat, carbohydrates and calcium, while correlations for niacin, riboflavin and thiamin ranged from 0.47 to 0.40 . The concordance correlation coefficient ranged from 0.59 for fat to 0.06 for vitamin C.

After adjustment for energy, Pearson correlations decreased, ranging from 0.59 for carbohydrates to 0.11 for thiamin and vitamin $\mathrm{C}$, and the concordance correlation coefficients for energy-adjusted nutrients ranged from 0.49 for fat to 0.06 for protein. After adjusting for residual measurement error, the correlations increased as expected, ranging from 0.84 (calcium) to 0.19 (vitamin C). The improvement in the correlation as a result of

Table 1 Intakes of energy and selected nutrients from multiple 24-hour recalls and a semi-quantitative food-frequency questionnaire in 73 adults, aged $22-55$ years, in four communities of El Progreso district, Guatemala

\begin{tabular}{|c|c|c|c|c|c|}
\hline \multirow[b]{2}{*}{ Nutrient } & \multicolumn{2}{|c|}{ 24-hour dietary recalls } & \multicolumn{2}{|c|}{$\begin{array}{c}\text { Semi-quantitative } \\
\text { food-frequency questionnaire }\end{array}$} & \multirow[b]{2}{*}{$P$} \\
\hline & Mean & SD & Mean & SD & \\
\hline Energy (kcal)† & 2064 & 541 & 2425 & 580 & * \\
\hline Protein (g) & 59 & 16 & 74 & 21 & * \\
\hline Fat $(\mathrm{g})$ & 44 & 21 & 51 & 20 & ** \\
\hline Carbohydrates (g) & 369 & 94 & 431 & 100 & * \\
\hline Calcium (mg) & 816 & 251 & 1039 & 388 & *** \\
\hline Iron (mg) & 11.1 & 4.0 & 15.4 & 5.2 & * \\
\hline Thiamin (mg) & 1.1 & 0.4 & 1.5 & 0.4 & * \\
\hline Riboflavin (mg) & 0.8 & 0.3 & 1.1 & 0.5 & * \\
\hline Niacin (mg) & 12.1 & 4.0 & 15.2 & 4.7 & * \\
\hline Vitamin C (mg) & 64 & 110 & 213 & 213 & * \\
\hline Vitamin A ( $\mu \mathrm{g}$ RE $\ddagger$ ) & 845 & 451 & 1655 & 1094 & * \\
\hline
\end{tabular}

SD - standard deviation.

${ }^{*}, P<0.05 ;{ }^{* *}, P<0.01,{ }^{* * *}, P<0.001$ by paired $t$-test.

† To convert kcal to MJ, multiply by 0.004184 .

$\ddagger$ Retinol equivalents. 
Table 2 Correlations of energy, nutrients and energy-adjusted nutrients obtained using 24-hour dietary recall and a food-frequency questionnaire among 73 adults, aged 22-55 years, in four communities of El Progreso, Guatemala

\begin{tabular}{|c|c|c|c|c|c|c|}
\hline \multirow[b]{2}{*}{ Nutrient } & \multicolumn{3}{|c|}{ Not adjusted for energy intakes } & \multicolumn{3}{|c|}{ Energy-adjusted } \\
\hline & $\begin{array}{l}\text { Pearson } \\
\text { correlation }\end{array}$ & $\begin{array}{c}\text { Corrected } \\
\text { for measurement } \\
\text { error }\end{array}$ & $\begin{array}{l}\text { Concordance } \\
\text { correlation } \\
(95 \% \mathrm{Cl})\end{array}$ & $\begin{array}{l}\text { Pearson } \\
\text { correlation }\end{array}$ & $\begin{array}{c}\text { Corrected } \\
\text { for measurement } \\
\text { error }\end{array}$ & $\begin{array}{l}\text { Concordance } \\
\text { correlation } \\
(95 \% \mathrm{Cl})\end{array}$ \\
\hline Energy (kcal) & $0.64^{\star * \star}$ & 0.72 & $0.53(0.38,0.67)$ & & & \\
\hline Protein (g) & $0.53^{\star \star \star}$ & 0.64 & $0.38(0.23,0.53)$ & 0.17 & 0.22 & $0.06(-0.02,0.13)$ \\
\hline Fat $(\mathrm{g})$ & $0.63^{\star \star \star}$ & 0.73 & $0.59(0.44,0.74)$ & $0.56^{\star \star \star}$ & 0.66 & $0.49(0.33,0.65)$ \\
\hline Carbohydrates (g) & $0.63^{\star \star \star}$ & 0.71 & $0.53(0.38,0.68)$ & $0.59^{\star \star \star}$ & 0.70 & $0.22(0.14,0.30)$ \\
\hline Calcium (mg) & $0.52^{* \star *}$ & 0.67 & $0.42(0.26,0.58)$ & $0.43^{* * *}$ & 0.84 & $0.26(0.12,0.40)$ \\
\hline Iron (mg) & $0.38^{* *}$ & 0.45 & $0.26(0.11,0.41)$ & 0.21 & 0.38 & $0.10(-0.01,0.21)$ \\
\hline Thiamin (mg) & $0.40^{\star \star \star}$ & 0.52 & $0.31(0.14,0.48)$ & 0.11 & 0.26 & $0.06(-0.06,0.17)$ \\
\hline Riboflavin (mg) & $0.44^{\star \star \star}$ & 0.52 & $0.33(0.16,0.50)$ & $0.42^{\star \star \star}$ & 0.49 & $0.27(0.13,0.42)$ \\
\hline Niacin (mg) & $0.47^{\star \star \star}$ & 0.67 & $0.37(0.20,0.53)$ & 0.18 & $\dagger$ & $0.10(-0.03,0.23)$ \\
\hline Vitamin C (mg) & 0.12 & 0.22 & $0.06(-0.06,0.18)$ & 0.11 & 0.19 & $0.05(-0.06,0.16)$ \\
\hline Vitamin A ( $\mu \mathrm{g}$ RE $\ddagger)$ & $0.30^{*}$ & 0.41 & $0.18(0.04,0.31)$ & $0.30^{*}$ & 0.48 & $0.15(0.03,0.28)$ \\
\hline
\end{tabular}

$95 \% \mathrm{Cl}-95 \%$ confidence interval.

*, $P<0.05 ;{ }^{\star *}, P<0.01 ;{ }^{\star \star *}, P<0.001$.

$\dagger$ Ratio of intra-individual and inter-individual variance exceeds 90 ; calculated deattenuated correlation coefficient $>1.00$.

$\ddagger$ Retinol equivalents.

adjustment for residual error was particularly notable for calcium, presumably due to high within-person variability in intake of this nutrient.

The proportion of individuals classified by the FFQ and 24-hour recalls into the same quartile for energy and crude nutrient intakes ranged from $48 \%$ for calcium to $25 \%$ for vitamin C (Table 3). Concordance of classification of individuals into the same or adjacent quartiles by both methods ranged from $90 \%$ for fat to $71 \%$ for iron. The percentage of individuals grossly misclassified (those classified in the highest quartile by one method and the lowest quartile by the other) ranged from 1\% (energy, protein, protein, fat, carbohydrates) to $10 \%$ for vitamin C. For energy-adjusted nutrients, percentages of individuals classified in the same quartile for both methods ranged from $42 \%$ (fat) to $23 \%$ (vitamin C), while $64 \%$ (niacin) to $82 \%$ (carbohydrates) were classified into the same or adjacent quartile based on both methods. Grossly misclassified individuals ranged from $1 \%$ (energy-adjusted fat) to $12 \%$ (energy-adjusted thiamin).

\section{Contribution of food groups to total energy intake}

Table 4 presents 25 food groups identified as the major sources of energy in the diet, ranked by their contribution to energy intake as estimated from the 24-hour dietary recalls. These food groups were compiled from responses to the 24-hour recalls and FFQ, and do not necessarily represent single foods as recorded on either instrument. Tortillas and bread were the two main sources of energy by both dietary assessment approaches. Beans, eggs and chicken ranked higher according to the 24-hour recall than according to the FFQ. The contribution of tortillas to total energy consumption was estimated at $42 \%$ by 24 -hour dietary recall and $37.6 \%$ by FFQ $(P<0.001)$. The energy

Table 3 Cross-classification of 73 individuals by quartiles of energy and other nutrients obtained using multiple 24-hour dietary recalls and a semi-quantitative food-frequency questionnaire, El Progreso, Guatemala

\begin{tabular}{|c|c|c|c|c|c|c|}
\hline \multirow[b]{2}{*}{ Nutrient } & \multicolumn{3}{|c|}{ Not adjusted for energy intakes } & \multicolumn{3}{|c|}{ Adjusted for energy intake } \\
\hline & $\begin{array}{c}\text { Correctly } \\
\text { classified } \\
(\%)^{\star}\end{array}$ & $\begin{array}{c}\text { Same or adjacent } \\
\text { quartile } \\
(\%)\end{array}$ & $\begin{array}{c}\text { Grossly } \\
\text { misclassified } \\
(\%) \dagger\end{array}$ & $\begin{array}{l}\text { Correctly } \\
\text { classified } \\
(\%)\end{array}$ & $\begin{array}{c}\text { Same or adjacent } \\
\text { quartile } \\
(\%)\end{array}$ & $\begin{array}{c}\text { Grossly } \\
\text { misclassified } \\
(\%)\end{array}$ \\
\hline Energy (kcal) & 41 & 88 & 1 & - & - & - \\
\hline Protein (g) & 40 & 81 & 1 & 36 & 74 & 11 \\
\hline Fat $(g)$ & 41 & 90 & 1 & 42 & 77 & 1 \\
\hline Carbohydrates (g) & 36 & 85 & 1 & 38 & 82 & 4 \\
\hline Calcium (mg) & 48 & 89 & 3 & 38 & 78 & 3 \\
\hline Iron (mg) & 36 & 71 & 5 & 33 & 74 & 10 \\
\hline Thiamin (mg) & 40 & 77 & 3 & 26 & 66 & 12 \\
\hline Riboflavin (mg) & 41 & 79 & 8 & 29 & 78 & 3 \\
\hline Niacin (mg) & 40 & 81 & 5 & 33 & 64 & 7 \\
\hline Vitamin C (mg) & 25 & 74 & 10 & 23 & 70 & 8 \\
\hline Vitamin A ( $\mu g$ RE $\ddagger)$ & 27 & 77 & 9 & 33 & 73 & 8 \\
\hline
\end{tabular}

* Same quartile using both methods.

† Highest quartile using one method and lowest quartile using second method.

$\ddagger$ Retinol equivalents. 
Table 4 Major sources of energy in the diets of 73 adults, aged 22-55 years, in four communities of El Progreso, Guatemala, 24-hour recall vs. semi-quantitative food-frequency questionnaire

\begin{tabular}{|c|c|c|c|c|c|c|c|}
\hline \multirow[b]{3}{*}{ Food group $†$} & \multicolumn{5}{|c|}{ Mean contribution of food group to total energy intake (\%) } & & \\
\hline & \multicolumn{2}{|c|}{ 24-hour recall } & \multicolumn{2}{|c|}{$\begin{array}{c}\text { Semi-quantitative } \\
\text { food-frequency } \\
\text { questionnaire }\end{array}$} & \multirow[b]{2}{*}{$P$} & \multicolumn{2}{|c|}{ Agreement across methods } \\
\hline & Mean & SD & Mean & SD & & Pearson & $\begin{array}{l}\text { Concordance } \\
(95 \% \mathrm{Cl})\end{array}$ \\
\hline Tortillas & 42.9 & 13.1 & 37.6 & 13.0 & $<0.001$ & $0.59^{\star \star \star}$ & $0.54(0.34,0.70)$ \\
\hline Bread & 12.0 & 8.8 & 12.6 & 7.8 & & $0.52^{\star \star \star}$ & $0.52(0.35,0.69)$ \\
\hline Sugar & 8.1 & 4.2 & 2.7 & 2.1 & $<0.001$ & 0.15 & $0.05(-0.03,0.13)$ \\
\hline Beans & 8.0 & 4.4 & 8.7 & 7.8 & & $0.27^{*}$ & $0.25(0.05,0.46)$ \\
\hline Other foods & 4.5 & 5.6 & 2.5 & 3.0 & & 0.19 & $0.15(-0.03,0.32)$ \\
\hline Rice & 2.5 & 3.1 & 3.6 & 2.9 & & $0.29^{*}$ & $0.27(0.07,0.48)$ \\
\hline Eggs & 2.3 & 2.3 & 2.4 & 2.5 & & $0.43^{\star *}$ & $0.43(0.24,0.64)$ \\
\hline Chicken & 2.1 & 2.9 & 2.1 & 1.7 & & $0.29^{*}$ & $0.25(0.06,0.44)$ \\
\hline Oil and fats & 2.0 & 2.4 & 0.2 & 0.8 & $<0.001$ & 0.18 & $0.08(-0.02,0.17)$ \\
\hline Pasta & 1.9 & 3.6 & 1.7 & 1.6 & & $0.25^{*}$ & $0.18(0.02,0.35)$ \\
\hline Prepared dishes & 1.7 & 3.3 & 4.1 & 3.9 & $<0.001$ & 0.10 & $0.08(-0.11,0.27)$ \\
\hline Pork & 1.6 & 3.4 & 2.3 & 2.3 & & $0.39^{\star \star \star}$ & $0.35(0.17,0.54)$ \\
\hline Vegetables & 1.6 & 1.6 & 2.6 & 4.3 & & 0.07 & $0.04(-0.10,0.19)$ \\
\hline Fruits & 1.5 & 3.4 & 4.6 & 4.6 & & 0.02 & $0.01(-0.15,0.19)$ \\
\hline Carbonated beverages & 1.3 & 2.4 & 1.4 & 1.6 & & $0.56^{\star \star \star}$ & $0.51(0.36,0.66)$ \\
\hline Sour cream & 1.0 & 1.7 & 0.7 & 0.6 & & 0.13 & $0.08(-0.06,0.22)$ \\
\hline Potatoes & 1.0 & 1.7 & 4.1 & 4.2 & $<0.001$ & 0.10 & $0.05(-0.06,0.15)$ \\
\hline Beef & 0.9 & 1.9 & 1.1 & 1.2 & & $0.24^{\star}$ & $0.20(0.02,0.40)$ \\
\hline Sugared beverages & 0.8 & 1.9 & 1.1 & 1.4 & & 0.01 & $0.01(-0.20,0.23)$ \\
\hline Milk & 0.8 & 2.0 & 1.8 & 3.5 & & $0.23^{*}$ & $0.19(0.01,0.37)$ \\
\hline Coffee & 0.6 & 0.6 & 0.4 & 0.2 & $<0.001$ & $0.56^{\star \star \star}$ & $0.35(0.22,0.48)$ \\
\hline Cheese & 0.6 & 1.1 & 0.1 & 0.1 & & 0.16 & $0.04(-0.02,0.09)$ \\
\hline Salted Snacks & 0.3 & 0.9 & 1.0 & 1.5 & $<0.001$ & $0.43^{\star \star \star}$ & $0.32(0.16,0.48)$ \\
\hline Preserves and sweets & 0.0 & 0.1 & 0.5 & 0.8 & $<0.001$ & $0.52^{\star \star \star}$ & $0.14(0.07,0.20)$ \\
\hline
\end{tabular}

SD - standard deviation; $95 \% \mathrm{Cl}-95 \%$ confidence interval.

${ }^{*}, P<0.05 ;{ }^{* *}, P<0.01 ;{ }^{* * *}, P<0.001$.

†Foods ranked according to their contribution to total energy intake as estimated from 24-hour recalls.

contribution of sugar and of oil and fats also differed markedly between the two methods (the 24-hour method produced higher values), probably because the 24-hour recalls include these items when used in food preparation while the FFQ does not. Similarly, estimates of energy contributed by prepared dishes were greater from the 24hour recalls than from the FFQ.

The FFQ method resulted in an apparently more varied diet, presenting fruits and vegetables in a higher rank than did the use of 24-hour dietary recalls, but only for fruits was the difference in contribution to total energy intake significant $(P<0.001)$.

Contribution to energy intakes from coffee, cheese, salted snacks, jams and sweets consumption differed between the two methods (with no consistent pattern), but these foods each accounted for only $1 \%$ or less of total energy intake.

Pearson coefficients greater than 0.50 were observed for tortillas, bread, jams and sweets, carbonated beverages and coffee. Correlations were low for cheese, sour cream, vegetables, fruits, potatoes, sugar, sugared beverages, oils and fats and prepared dishes. Concordance coefficients ranged from 0.54 for tortillas to 0.01 for fruits and sugared beverages.

\section{Discussion}

In this study, the validity of a semi-quantitative FFQ for use in adults in El Progreso, Guatemala, was examined. Correlations that are considered as desirable for these kinds of study tend to be from 0.5 to $0.7^{1}$. Specifically, our study suggests that this FFQ is a useful instrument for assessing intakes of energy and macronutrients $(r=0.64$ to 0.53 ) and of selected micronutrients (calcium, thiamin, riboflavin and niacin, Pearson coefficients ranging from 0.52 to 0.40 ).

Adjustment for energy intake and residual measurement error in the dietary recalls affected the correlation coefficients. To the extent that inter-individual differences in energy intake exist, these will result in spurious variance in intakes of nutrients of interest; hence adjustment of both methods for energy intake should reduce variance in both measures, and reduce the power to detect associations. Bias in reporting energy intakes is not separable, in this analysis, from true inter-individual differences. In the present study, after adjusting for energy intake, Pearson correlation coefficients for protein, fat, carbohydrates, calcium, iron, thiamin, riboflavin and niacin all decreased compared with the non-adjusted correlations. These 
findings suggest that variation in these nutrients is related to the energy variation.

A study such as ours compares two flawed methods to one another, rather than a method to a true gold standard. The mean of three 24-hour dietary recalls may not represent an individual's true intake. Specifically, iron, vitamin $\mathrm{C}$ and vitamin A all had correlation coefficients $<0.40$; use of an increased number of 24-hour dietary recalls might have better reflected the day-to-day variation in intake of those micronutrients. Indeed, correction for attenuation due to residual measurement error resulted in notably higher point estimates for these nutrients.

Our results support specific adaptations of an FFQ to local cultural conditions. Specifically, we used openended portion sizes for Guatemala's 'core foods' (tortilla, bread and beans) for which inter-individual variability is large; a similar approach was used in a study of the diets of Puerto Ricans in the United States ${ }^{18}$. An earlier FFQ, developed for schoolchildren in Guatemala, yielded very low concordance coefficients ( 0.14 for energy, 0.21 for protein, 0.01 for iron and 0.01 for retinol $)^{23}$, but that instrument used a design developed for epidemiological studies in the United States ${ }^{1,24}$.

The FFQ had a good ability to classify individuals according to intakes of energy and other nutrients in the same or adjacent quartile as the 24 hour-recall: $>80 \%$ of individuals were so classified for energy intake and crude intakes of calcium and niacin; other micronutrients ranged from 71 to $79 \%$. Individuals correctly classified in the same quartile for both methods ranged from a high of $48 \%$ for calcium to $<30 \%$ for vitamin C. For riboflavin, vitamin C and vitamin $\mathrm{A},>5 \%$ of individuals were grossly misclassified. After adjusting for energy intakes, $<30 \%$ of individuals were classified correctly for thiamin, riboflavin and vitamin C. These results are comparable to those of other studies ${ }^{1,3,15}$ and may reflect insensitivity of the instrument(s) or inconsistencies in the food composition database (although this explanation is unlikely as the same database was used for both instruments).

Analysis of food groups can be complex, but it can provide useful information about how food groups are eaten in the population under study. Such comparisons may be particularly helpful in focusing attention to questionnaire items that are performing particularly well or poorly. Interpretation is complicated because foods are usually recorded in more detail in the 24-hour recalls, so these individual foods need to be combined to correspond to items on the food-frequency questionnaire. Furthermore, day-to-day variation in intakes of specific foods is substantially greater than variation in nutrients ${ }^{1}$. Estimates of energy intakes from fruits and vegetables correlated poorly across the two methods $(P>0.05)$, and this is probably because three 24-hour recalls were still inadequate to account for the high variability of consumption of these foods.

Stronger correlations were found for tortillas, bread, carbonated beverages, coffee, preserves and sweets, salted snacks, eggs and pork products, than for chicken and animal products. One reason for this might be the increased variance in consumption of these products. One of the disadvantages of any FFQ is that food ingredients and preparation methods are not fully accounted for. This may explain the poor agreement between estimates of energy from sugar and from oil and fats, which were included as part of recipes incorporated into the 24-hour recall methods but not identified as ingredients in mixed dishes using the FFQ.

Our study has several limitations that must be considered. First, the final dataset for analysis consists of 73 individuals, reducing our ability to analyse the data for men and women separately and resulting in point estimates with lower-than-ideal precision. We did not administer an FFQ at the onset of the study, and cannot therefore assess the reproducibility of the instrument. Three days of recalls are not a gold standard, especially for micronutrients that require more days of record to satisfactorily dampen day-to-day variability. Most selfreport dietary assessment methods may be biased ${ }^{25,26}$, underestimating true intake. Thus we do not know the true degree of bias, if any, in the absolute values derived from the FFQ. Finally, there may be correlated errors that would result in spurious inflation of estimates of correlation, namely the fact that both methods are dependent upon recall, and nutrient estimates were derived from the same nutrient database. We note that these sources of error are common to all validations of FFQ instruments that use 24-hour dietary recalls as the reference.

In conclusion, this FFQ appears to be a useful tool for estimation of dietary intakes for research, especially for epidemiological studies of diet as a risk factor for cardiovascular disease and other chronic diseases, and for dietary surveillance in Guatemala. Such studies are important in Latin America, where some countries have overcome high undernutrition prevalence among their populations but now experience the emergence of chronic diseases associated with diets high in energy density and fat composition. While we expect the instrument to be broadly applicable to other populations in Central America, additional research is warranted to assess whether this instrument performs as well in periurban and urban areas in Guatemala or elsewhere in Central America, and we recommend that potential users conduct a validation-calibration study prior to instrument adoption.

\section{Acknowledgements}

We are grateful to Edelmira Martinez, Adela Sanchez and Blanca Sulecio for data collection activities and to Robert Houser and Katherine Tucker of the School of Nutrition, Tufts University for their comments. Funding for this 
project was provided by the National Institutes of Health (USA) and the Nestle Foundation (Switzerland).

\section{References}

1 Willett W. Nutritional Epidemiology, 2nd ed. Oxford: Oxford University Press, 1998.

2 Hernandez-Avila M, Romieu I, Parra S, Hernandez-Avila J, Madrigal H, Willett W. Validity and reproducibility of a food frequency questionnaire to assess dietary intake of women living in Mexico City. Salud Publica Mex. 1998; 40: 133-40.

3 Bingham SA, Gill C, Welch A, et al. Comparison of dietary assessment methods in nutritional epidemiology: weighed records v. $24 \mathrm{~h}$ recalls, food-frequency questionnaires and estimated-diet records. Br. J. Nutr. 1994; 72: 619-43.

4 Bingham SA. Dietary assessments in the European prospective study of diet and cancer (EPIC). Eur.J. Cancer Prev. 1997; 6: $118-24$.

5 Egami I, Wakai K, Kato K, et al. A simple food frequency questionnaire for Japanese diet - Part II. Reproducibility and validity for nutrient intakes. J. Epidemiol. 1999; 9: 227-34.

6 Forman MR, Zhang J, Nebeling L, et al. Relative validity of a food frequency questionnaire among tin miners in China: 1992/93 and 1995/96 diet validation studies. Public Health Nutr. 1999; 2: 301-15.

7 Hebert JR, Gupta PC, Bhonsle RB, et al. Development and testing of a quantitative food frequency questionnaire for use in Kerala, India. Public Health Nutr. 1999; 2: 39-50.

8 Klipstein-Groubusch K, den Breeijen JH, Goldbohm RA, Geleijnse JM, Hofman A, Grobbee DE, Witteman JCM. Dietary assessment in the elderly: validation of a semiquantitative food frequency questionnaire. Eur. J. Clin. Nutr. 1998; 52: 588-96.

9 Lemaitre RN, King IB, Patterson RE, Psaty BM, Kestin M, Heckbert SR. Assessment of trans-fatty acid intake with a food frequency questionnaire and validation with adipose tissue levels of trans-fatty acids. Am.J. Epidemiol. 1998; 148 : 1085-93.

10 Wei ED, Gardner J, Fiel AE, Rosner BA, Colditz GA, Suitor $\mathrm{CW}$. Validity of a food frequency questionnaire in assessing nutrient intakes of low-income pregnant women. Matern. Child Health J. 1999; 3: 241-6.

11 Willett WC, Sampson L, Stampfer MJ, et al. Reproducibility and validity of a semi-quantitative food frequency questionnaire. Am. J. Epidemiol. 1985; 122: 51-65.

12 Willett WC, Reynolds RD, Cottrell-Hoehners S, Sampson L, Brown ML. Validation of a semi-quantitative food frequency questionnaire: comparison with a 2 -year diet record. J. Am. Diet. Assoc. 1987; 87: 43-7.

13 Green T, Allen OB, O'Connor D. A three-day weighed food record and a semiquantitative food-frequency questionnaire are valid measures for assessing the folate and vitamin B-12 intakes of women aged 16 to 19 years. J. Nutr. 1998; 128: 1665-71.

14 Cassidy CM. Walk a mile in my shoes: culturally sensitive food-habit research. Am. J. Clin. Nutr. 1994; 59(Suppl.): 190S-7S.

15 Torheim LE, Barikmo I, Hatløy A, Diakité M, Solvoll K, Diarra $M$, Oshaug A. Validation of a quantitative food frequency questionnaire for use in Western Mali. Public Health Nutr. 2001; 4(6): 1267-77.

16 Romieu I, Parra S, Hernandez JF, Madrigal H, Willett W, Hernandez M. Questionnaire assessment of antioxidants and retinol intakes in Mexican women. Arch. Med. Res. 1999; 30: 224-39.

17 INE-CADESCA-SEGEPLAN. Encuesta Nacional de Consumo Aparente de Alimentos, 1991. Guatemala: INECADESCA-SEGEPLAN, 1992; 62 pp.

18 Tucker KL, Bianchi L, Maras J, Bermudez O. Adaptation of a food frequency questionnaire to assess diets of Puerto Rican and non-Hispanic adults. Am. J. Epidemiol. 1998; 148: 507-18.

19 Menchú MT. Guía Metodológica para realizar Encuestas Familiares de Consumo de Alimentos. Guatemala: Instituto de Centro América y Panamá, 1990; 92 pp.

20 Menchu MT, Mendez H, Barrera MA, Ortega L. Tabla de Composicion de Alimentos de Centro America - Primera Seccion. Guatemala: INCAP/OPS, 1996.

21 Lin LI. A concordance correlation coefficient to evaluate reproducibility. Biometrics 1989; 45: 255-68.

22 Bland JM, Altman DG. Comparing methods of measurement: why plotting difference against standard method is misleading. Lancet 1995; 346: 1085-7.

23 Rodríguez MM. Evaluación dietética de grupos de escolares de diferentes establecimientos educativos mediante la aplicación de dos métodos de consumo de alimentos. Thesis, Facultad de Ciencias Químicas y Farmacia, Universidad de San Carlos de Guatemala, 1992.

24 Block G, Hartman AM, Dresser CM, Carroll MD, Gannon J, Gardner L. A data based approach to diet questionnaire design and testing. Am. J. Epidemiol. 1986; 24: 453-69.

25 Black AE, Goldberg GR, Jebb SA, Livingstone MB, Cole TJ, Prentice AM. Critical evaluation of energy intake data using fundamental principles of energy physiology. 2. Evaluating the results of published surveys. Eur.J. Clin. Nutr. 1991; 45: 583-99.

26 Kroke A, Klipstein-Grobusch K, Voss S, Moseneder J, Thielecke F, Noack R, Boeing $H$. Validation of a selfadministered food-frequency questionnaire administered in the European Prospective Investigation into Cancer and Nutrition (EPIC) Study: comparison of energy, protein, and macronutrient intakes estimated with the double labeled water, urinary nitrogen, and repeated 24-h dietary recall methods. Am. J. Clin. Nutr. 1999; 70: 439-47. 
Appendix - List of the 52 food items ascertained in the INCAP food-frequency questionnaire

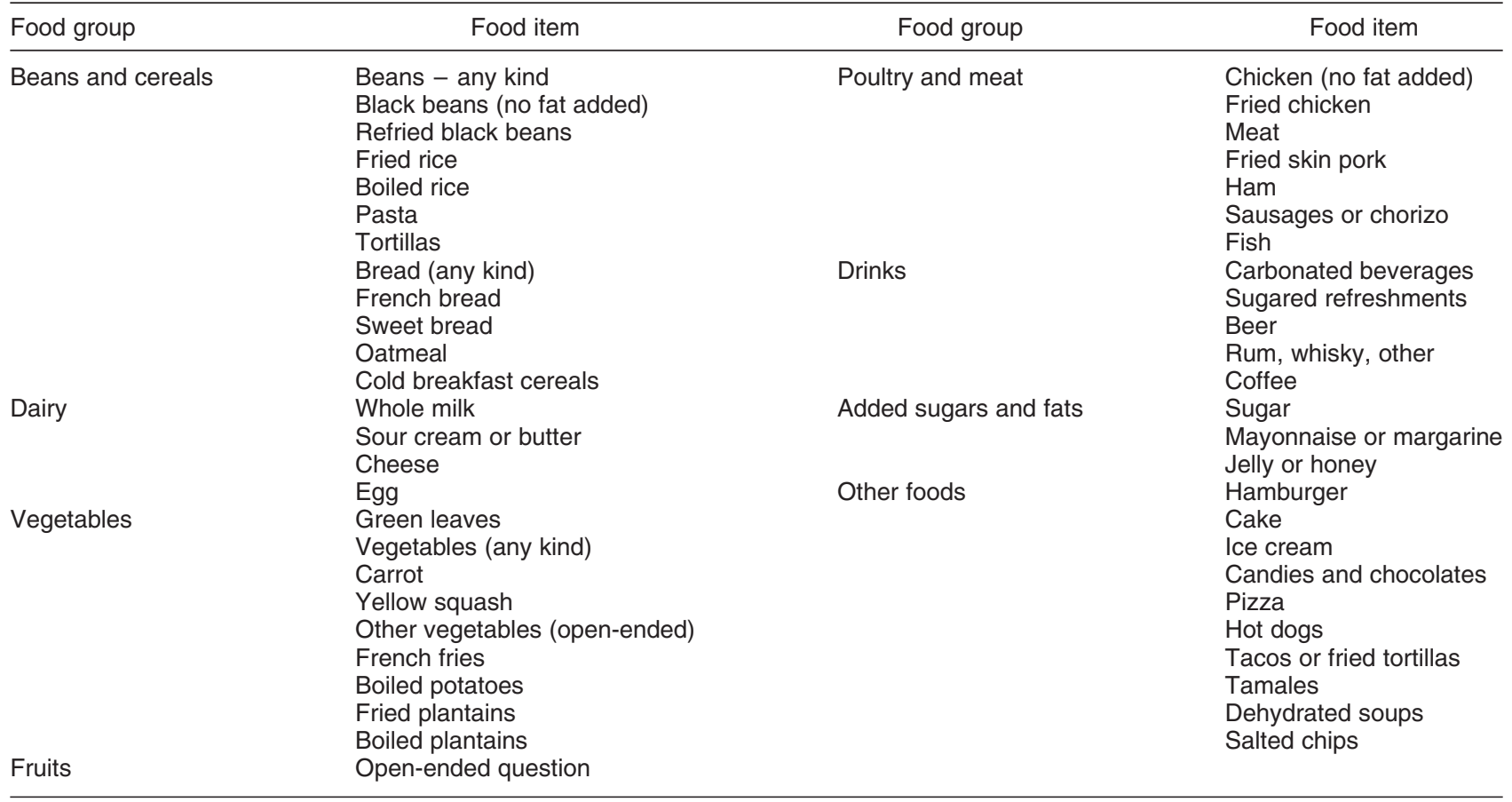

